\title{
Managing Innovation in the Sports Equipment Industry: Upstream Process Management
}

\author{
Yann Abdourazakou \\ California State University, Dominguez Hills, USA
}

\begin{abstract}
The point under study is the first of such a nature. This paper investigates the management of innovation adopted by the European leader in sports equipment: Decathlon (Oxylane Group). In recent years, vertical integration push and innovation have secured the company's leadership and success in a number of sports markets throughout Europe. It now has 909 stores located globally. Oxylane Group designs, manufactures, and sells sports products for sports people worldwide. It offers fitness, dance, gymnastics, and combat sports products; bicycles, equipment, and accessories; team sports products; nautical and water sports products (surf sports, diving, sailing, and kayaking products); swimming products; mountain sports products (for hiking, mountain trailing, camping, skiing, and snow shoe hiking); skiing and snowboarding products (for snowboarders and skiers); and climbing and mountaineering products. The company is now a direct challenger for world sports leaders. Since the end of the 1990's, Decathlon different sports brands have not taken a unique and rational path to success. The company has built insights about its customers, identified and evaluated unique market opportunities, and prepared a bold game plan to seize them. By doing so, Decathlon has developed a stream of winning products. The process of new business creation generally splits into two parts: an upstream process (sensing and creating opportunities) and a downstream process (converting the selected opportunities into successful products). Most businesses have a formal process implemented to manage the downstream part. Few that people know of have set up an equivalent process like Oxylane and Decathlon to sense and create new opportunities in the sports equipment industry. The aim of the paper is to examine how the brand has developed two of its successful product: the tent two seconds and the wetsuit "Inergy". These two products are chosen as examples to understand how the upstream process articulate with the downstream one.
\end{abstract}

Keywords: innovation, sports equipment, process, management

\section{Introduction}

Managing innovation in a company varies according to the peculiarity of its industry. These characteristics can go as far as being specific to the company itself (Smallbone, Leigh, \& North, 1995). An important part of the variation observed depends especially on the personality of the "discover-owner" (Smallbone et al., 1995; Autio \& Lume, 1998). Innovation commonly splits between product innovation and process innovation (Abernathy \& Utterback, 1978). The concept of lifecycle highlights two main paths companies usually pursued in the process of innovating: continuity in order to exploit an opportunity or to look to discontinue past actions by sensing new opportunities (Autio \& Lume, 1998). The firm thus manages its innovation process by

Yann Abdourazakou, Ph.D., associate professor, California State University, Dominguez Hills, USA.

Correspondence concerning this article should be addressed to Yann Abdourazakou, California State University, Dominguez Hills, 1000 E. Victoria St., Carson 90747, USA. E-mail: yabdourazakou@ @ csudh.edu. 
exploiting existing sources and exploring unknown horizons. However, two traps lie in wait for the company going through the innovation process: that of failure and that of success (Rothaermel, 2012). The result is not simply the consequence of the activities of research and development (R\&D) but a process, which will engender uncertainty and instability. Those two aspects entail new skills development, modification of the distribution of resources, and re-evaluation of the strategic universe. In this context, two interactions co-exist. First, an initial interaction among different functions is involved at the upstream level and downstream level throughout the innovation process. Second, another interface is at stake between the company going through the innovation process and its environment. This study carried out the collection of data combined with documentary analysis and interviews. On this last aspect, the interview as collection method of primary data was chosen because of its absence of formalism. According to the authors, this method, not very directive, seemed more adapted to an executive officer unfamiliar with more sophisticated techniques. By letting the interviewee structure his answer, it is relatively easy to understand its logic before rationalization of a posteriori. Moreover, the choice of the interview procedure makes it possible to establish a trust relationship with the interviewee, so that he can speak more easily about the innovations developed by its company. Based on the interviews, the resources based view (RBV) makes it possible to highlight the specific assets of a "hyperfirm" within its strategic development (Marchesnay, 1997).

\section{Assessing Innovation in Sports Equipment Through the RBV}

$\mathrm{RBV}$ is a model that sees resources as key to superior firm performance. If a resource exhibits VRIO attributes, the resource enables the firm to gain and sustain competitive advantage (Hamel, Amel, \& Prahalad, 1995). According to RBV proponents, it is much more feasible to exploit external opportunities using existing resources in a new way rather than trying to acquire new skills for each different opportunity. In RBV model, resources are given the major role in helping companies to achieve higher organizational performance. There are two types of resources: tangible and intangible. This study is based on the postulate that specific non-technological determinants of innovation, in particular, the organizational capabilities developed for innovation play a significant role in Decathlon success model. Which variables can explain the company's sustainable competitive advantage in sports equipment? What are the characteristics of the skills and assets? How do they combine with each other? The concepts of "resource" and "strategic assets" can help to answer those different questions by looking the company as a whole. In this context, they represent elementary entities defining a potential (Barney, 1991; Dierickx \& Cool, 1989; Petaraf, 1993; Wernerfelt, 1984). A resource is also a potential which must be used in the goal of creating value for the client. Resources are more or less complex to construct and acquire while assessing their power of differentiation stands as a major issue (Giard, 1991). From this point of view, a resource is an observable asset, which can be evaluated and exchanged while distinctive skills are an opportune combination of resources (Hitt \& Ireland, 1985; Petaraf, 1993). When different organizational resources and skills are heterogeneous, rare, and difficult to imitate or acquire, they are considered as strategic assets (Hamel et al., 1995). The principle of the RBV approach consists in modeling the company through a set of resources, which respected and combined lead to a certain number of specific organizational aptitudes (Métais, 1997). Developing a sustainable competitive advantage supposes having resources difficult for rivals to imitate and valued by customers within a complex process. Could rationality and chaos have given birth to a unique and inimitable position for Decathlon in the sports equipment industry? In 1995, Microsoft presented its "internet strategy" based on technologies brought together from within the 
Microsoft Network, which launched itself into a frontal attack against AOL (American online). Two years later, an executive in the company blocked by a snowstorm on a campus discovered how the students were surfing the web. He realized the monumental mistakes, which consisted for Microsoft of setting up an ownership type technology in a world that had become free and open. The email he sent to Bill Gates had monumental consequences, when its CEO decided to risk $\$ 300$ million and have 2,000 engineers working in a new division exclusively on the Internet. Above all, it shows that one characteristic related to the hypercompetitive environment requires flexibility and permeability to the environment. Today, the key to the strategy is a question of movement, change, adaptation, hesitations, seizing opportunities, and accompanying emergence (Thiétart, 2000). Some companies like 3M push towards instability and disorder where individual initiative and experiment are encouraged by letting employees work on whatever projects they want for 15 minutes every day without constraints. On the contrary, other forces lead to stability and order, for example, in companies, planning, monitoring, and structuring are forces, which encourage stability. Planning by favoring information and communication is a mean to deal with complexity. In companies, structures are here to create formal links among actors, to delegate responsibilities, and to clarify the allocation of tasks and actions. Therefore, they reinforce stability and continuity. Other forces can create instability and disorder like, for example, innovation rupture in style coming from competitors or a rupture in the rules governing competition. Some researchers have focused on the strategic vision (Hamel et al., 1995), others on the management of R\&D (Tarondeau, 1991), on the management of innovative projects (Giard, 1991), and finally on the marketing of innovation (Gaillard, 1997). These research findings have mainly been applied outside of the sport industry, which has some strong peculiarities. Sport encourages the consumption of goods with a strong technological added value, but it is also linked to symbolic values which are distinct from practical use only. The case of Decathlon seems to suggest that it is at the crossroads of rationality and chaos that sporting innovation is managed successfully.

\section{The Management of Innovation in the Sports Equipment Industry}

Innovative companies often rethink their management model through the allowance of freedom. This characteristic can create disorder that is every so often necessary to foster creativity and nurture innovation. However, this disorder also means that the company risks some consequences, like not controlling the outcome of such a process or culture. Based on two products, this paper examines the innovation processes and strategies in order to test two hypotheses:

H1: Innovation is an opportunity. It is a complex and unpredictable process requiring chaos and creativity;

H2: Innovation fulfils a need to solve a practical problem to attract new consumers in order to gain market shares, which requires a rational approach within the upstream and downstream processes.

Since its debut in 1997, the R\&D department Decathlon Creation Center has studied the human body in movement. Its goal is to improve safety, health, comfort, and fun of sportsmen and women. The director of innovation that people have met describes the innovation processes as being very macro. The later can be broken down into different stages.

The initial stage is called "vision". Its objective is to identify new targets and new approaches. In keeping with the brand's philosophy, this strategic step makes it possible to "define relevant targets with strong potential for innovation". Based on comments and reviews from the consumers and feedbacks from 594 stores in 19 countries, project directors define specifications for future sports products. The next step is the technical specifications defining components and assemblage procedures according to specifications. From there, the 
$R \& D$ department manages initial studies and launches the creation of the projects themselves. The head of industrial prototypes builds a first prototype to be tested in laboratories using torture tests, but also he tries out realistic conditions of usage on the field by testers club, a panel of customers. Thus, it is necessary to produce several prototypes before any decisions are made on the final product. The product is then perfected with a final list of technical specifications before being sent to the different countries where Decathlon production is located. Subcontractors undertake the production and it is their responsibility to supervise production and choose the supplying components to deliver a quality-end product. The last phase is the commercialization and communication where the company showcases its products to potential customers in shops, to the specialized news channels, and through advertising. The Decathlon Group has invented a model of business growth based primarily on the development of a portfolio made-up of new own brands. The weight of these stages can vary from one project to another, but the innovation process efficiency will get most of its substance out of this perfect union among these four circles of skills. Like the Head of Innovation at Decathlon told, there are products perfectly reflecting initial vision, others which will be great opportunities can upset the first part of the process but bring a revolution to the market. However, it is not wise to steadily mimic the same process for new sport equipment. This is why Decathlon tries to follow this general procedure described below:

You need quantity, you need a lot of ideas. The process requires trying different ways of enriching an idea in order to always be creative. I would say that Decathlon has a slightly chaotic and organic logic. It's not very structured. We try to think outside the box and whatever it costs we come up with something.

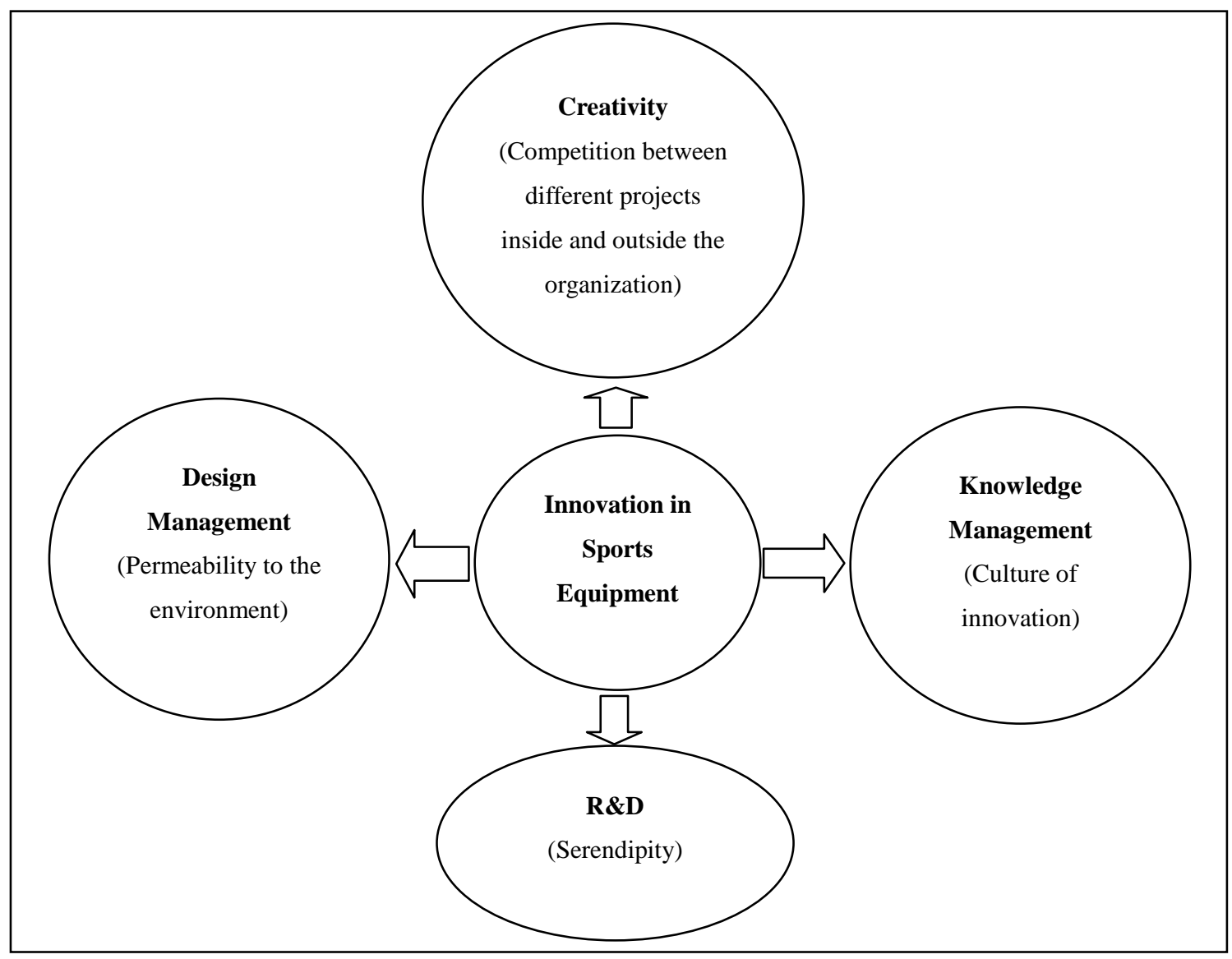

Figure 1. Four principles to manage innovation in sports equipment. 
This heterogeneity of projects has one goal: having successful products commercialized. It should be said that the general direction of the group puts its staff under pressure: The R\&D units are expected to concretize 10 innovations or so per annum. Ultimately, four guiding principles dictate the management innovation system implemented by the Decathlon Group (Figure 2): creativity, design management, knowledge management, and R\&D. These four principles would seal the cohesion and the interdependence of all the productive and operational divisions of the group.

\section{Decathlon's Innovation in Sports Equipments}

Starting from a vertical growth strategy, the Decathlon Group developed by creating new specialized brands and by launching a "federator" innovation process as well as an R\&D activity divided by sectors, not as a retailer owner of sub-brands, but as a manufacturer owner of ambitious and powerful autonomous brands. This strategy led to a dual system of innovation management, and finally, to a form of "variable geometry" management. This study will focus on the R\&D of the Decathlon Group, especially on how innovative ideas are created and managed. To a great extent, the success of the Decathlon Group innovations and "passion-brands" depends, first of all, on an excellent understanding and coordination among the various components of the company involved, and also on an atypical innovative projects management system like showed below in Figure 2.

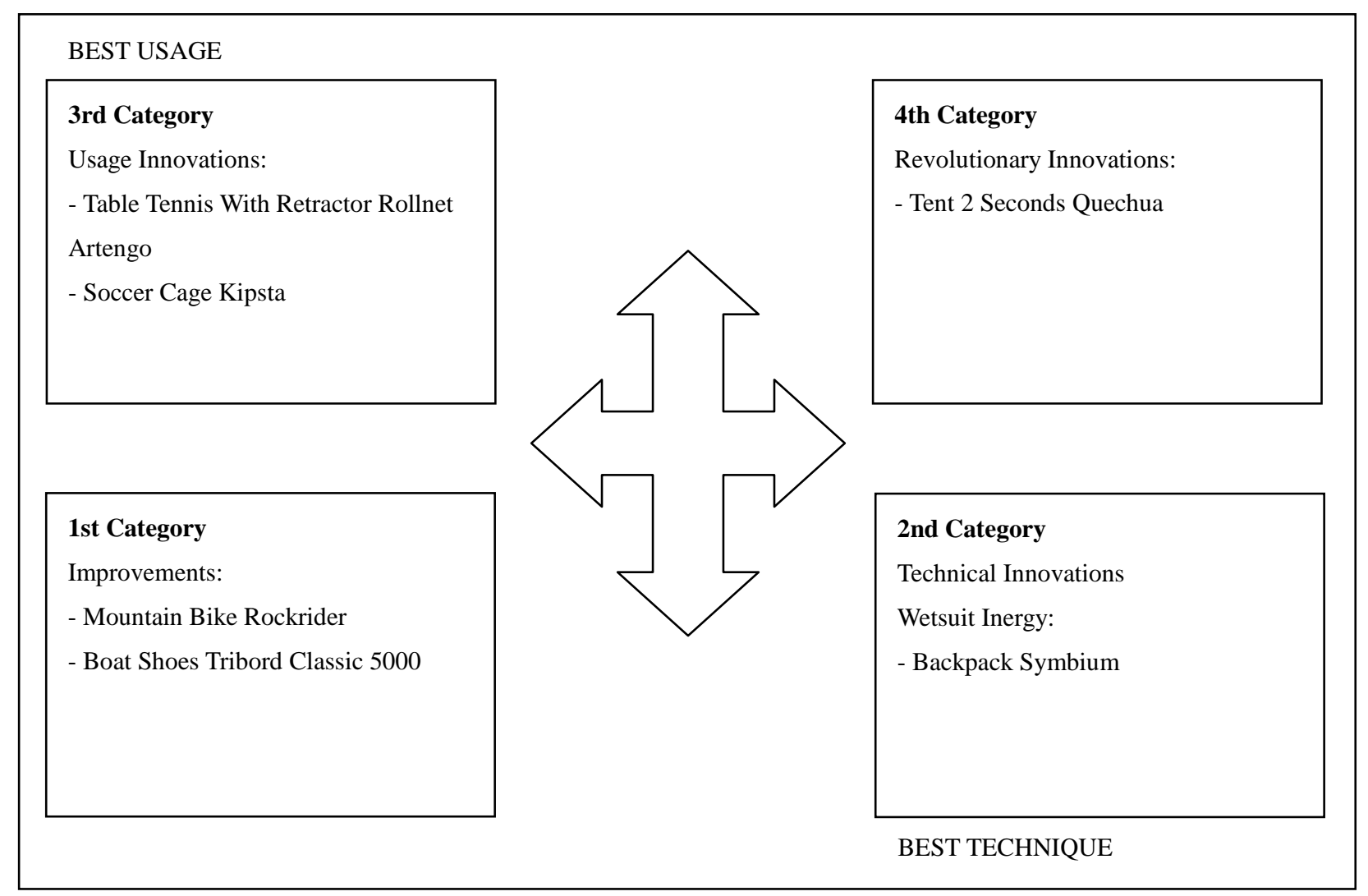

Figure 2. Decathlon innovation categories.

According to the approach by resources and the concept of "core competencies" (Hamel et al., 1995), it is possible to reconstruct ex ante an innovation approach. In modeling the act of the company, specific organizational skills are brought out (Métais, 1997). 


\section{The Case of the Quechua "Two Seconds" Tent}

Decathlon has created tents called "two seconds tent": this being the time it takes to set up the tent. It unfolds and sets up easily, considered spacious and compact to put away in is backpack. This new generation of tent was conceived in answer to multiple customer demands, rapid setting up, and as compact as possible for transportation. Its waterproofing was tested in laboratory and during mission test. An international patent was granted. On a practical level, all one has to do is to throw the tent into the air or place it on the ground and it unfolds itself. It only tales 10 seconds to fold it back again after use. Being disruptive on the market, the "two seconds tent" is categorized as a fourth category of innovation at Decathlon. Indeed, this tent has simplified the tents market so much that it has created a new need.

\section{The Case of the Wetsuit "Inergy"}

With technical partners of Tribord (sub brand of Decathlon), such as Nicholas Laydville (three times winner of the World Body-board championship) and Emmanuelle Joly (five times winner of the European Surfing Championship), the "Inergy" wetsuit allowed a total freedom of movement. For its production, numerous study of the human body in movement was carried out as well as a study of the skin using a scanner. Conceived for use in body board and surfing, the wetsuit is made out of Duramesh Neoprene, giving it maximum elasticity. This also limits freezing effect at the trunk level without interrupting the surfer's movement. This product was conceived to offer as many sensations as possible when in contact with the water and to guarantee at the same time an optimal thermal comfort, less fatigue. The "Inergy" wetsuit is categorized as a second category innovation at Decathlon. An international patent was also granted for this product.

\section{A Model of Innovation in Sports Equipment}

The two innovations had different paths within the Decathlon Group. The company creates incentives in order to obtain permeability and flexibility with the environment input. As its leader points out, innovation is entirely internal, when it is based on Decathlon creation (a division in charge of R\&D in the group). Director of Innovation said to maintain several forms of creativity during the project, therefore some options and ideas emerge along the way. He took the example of the wetsuit "Inergy":

It was the other project that had the upper hand and in fact there was a test phase and the results were worst than expected so we had to go to the original project and accelerate it. It was not a straight road so to speak there were institutionalized phases but also paradoxes and counter proposals.

Though, this innovation was based on an organized chaos with a certain amount of uncertainty. The issue for the company is that it has to fight inertia, as everyone is busy. As Director of Innovation said:

I cannot say I have got a great idea! There was a moment where we were glued and questioning ourselves, in fact the time necessary for us to decide according to people's time line and vision of what the product should look like.

Through these two examples of new products, it can be said that the rational innovation and ideas management system are quite appropriate for the expert goods, those that are located on specialized markets and which are intended for the informed and demanding sportsmen. With the Tribord Inergy wetsuit, the project-team started from a scientific and very conventional R\&D study on the elasticity of the skin to develop a wetsuit with the same properties. The study consisted in making tests with contact pads on a surfer's skin to know and model all its movements. Then, on the basis of acquired knowledge, the project-team sought to know which material would be the best to manufacture a wetsuit with high heating capacity and 
high elasticity (i.e., identification of all types of neoprene in terms of stretch, tonicity, seam gluing, and resistance, etc.). In this project, the objective was to improve the surfer's tonicity while using the elasticity of the materials in order to amplify the surfer's movements, in particular when he must paddle with his arms to take speed. In this project, it is the conjunction of several factors, which led to an innovation allowing the development of a new type of wetsuit to bring more freedom of movement and better protection of the surfer from the cold. The Decathlon Group had the will to become a leader and to show a high level of technical skill in the field of neoprene wetsuits. Thus, in order to achieve this goal, it included talented sports advisers in the project-team and made thorough scientific studies in biomechanics, physiology, and materials. The turbulent innovation and ideas management systems are more suited to general public goods, which require less technical training and scientific knowledge. Therefore, the innovation process gains in efficiency and allows the company to increase the launching of new goods. Today, an innovation project would be successful, thanks to movement, adaptation, back-ups, hesitations, opportunities caught at the right time, and especially a good support for new ideas (Thiétart, 2000). Extracts from the interview have shown that innovation management at Decathlon is centered on a freedom philosophy. Everything is set-up, so that creation and innovation are nurtured as much as possible without hierarchical or technical constraints. Director of Innovation underlined that it is very organic at Decathlon, it is not very structured, they really go for it and whatever happens they produce something, and it is like a brainstorming. Compared to the two innovations presented previously, R\&D innovation process at Decathlon follows a "semi-chaotic/semi-organic" reasoning. At the beginning, nothing appears really structured; the ideas can fuse in all directions. Once the green light of development is on, the company gives itself all the means to reach a satisfactory result, sometimes even exceeding all hopes (case of the "two seconds tent"). Today, the two-headed innovation and ideas management processes apply to all the "passion-brands". Therefore, the innovation process gains in efficiency and allows the company to increase the launching of new goods. Today, an innovation project would be successful, thanks to movement, adaptation, back-ups, hesitations, opportunities caught at the right time, and especially a good support for new ideas.

\section{Table 1}

Management Processes at Decathlon With Two Categories of Innovation

\begin{tabular}{|l|l|l|}
\hline & $\begin{array}{l}\text { Innovation and ideas management: Rational } \\
\text { process }\end{array}$ & $\begin{array}{l}\text { Innovation and ideas management: Turbulent } \\
\text { process }\end{array}$ \\
\hline Decathlon product & Inergy wetsuit & Two seconds tent \\
\hline Brand & Tribord & Quechua \\
\hline Innovation category & Second category & Fourth category \\
\hline Source of innovation & $\begin{array}{l}\text { Internal resources of the firm within the R\&D } \\
\text { department }\end{array}$ & $\begin{array}{l}\text { External resource combined with a project } \\
\text { manager concept }\end{array}$ \\
\hline Project timeline & Less than three years & More than 10 years \\
\hline Technical partner & $\begin{array}{l}\text { Yes } \\
\text { Body board champion and surf champion }\end{array}$ & $\begin{array}{l}\text { No inventor proposal competing with the } \\
\text { firm's R\&D }\end{array}$ \\
\hline Strategic goal & Market penetration & Creating a new market \\
\hline Innovation questions and issues & $\begin{array}{l}\text { Obtaining maximum elasticity and limiting } \\
\text { freezing feeling }\end{array}$ & $\begin{array}{l}\text { Adjusting a self unfolding concept with the } \\
\text { same comfort and space as competing } \\
\text { trademarks }\end{array}$ \\
\hline R\&D analysis & Internal knowledge (R\&D department) & Internal and external knowledge \\
\hline Patent & Yes & Yes \\
\hline
\end{tabular}




\section{Conclusions}

The original vision of innovation management is peculiar to the company, which does everything possible so that the projects come to reality. In their policy of innovation and growth, the Decathlon Group and their "passion-brands" gave themselves the freedom to choose between a stable and rational R\&D activity that allows the minimization of risks, but often to the detriment of a research that may be long and costly (i.e., "Inergy" wetsuit), and an unstable and turbulent R\&D activity which is potentially generating outstanding innovations having the capacity to modify an entire market segment (i.e., tent two seconds). At the frontier of rationality and chaos, this model is risky. Although Decathlon's idea generation and creation processes take place in a distorted way, the culture makes it possible for all the employees to follow a creative logic. Innovations resulting from the Decathlon Research Center R\&D and the "passion-brands" R\&D decentralized units follow different paths, according to whether they are located in specialized niches (water board sports for example) and intended for expert sportsmen (like body boarders and surfers) or located in non-specialized niches (like hiking and camping) intended for the general public (like vacationers and hikers). The creation of so different new goods is carried out, according to distinct strategic models. It is a complex approach towards innovation, since numerous projects are being launched at the same time and serendipity stakes are high; but when a promising niche market is discovered, the winner takes it all.

\section{References}

Abernathy, W. J., \& Utterback, J. M. (1978). Patterns of industrial innovation. Technology Review, 80, 16-30.

Autio, E., \& Lume, A. (1998). Does the innovator role affect the perceived potential for growth? Analysis of four types of new technology-based firms. Technology Analysis \& Strategic Management, 10, 41-54.

Barney, J. (1991). Firm resources and sustained competitive advantage. Journal of Management, 17, 99-120.

Dierickx, I., \& Cool, K. O. (1989). Asset stock accumulation and sustainability of competitive management. Management Science, 35(12), 1504-1511.

Gaillard, J. M. (1997). Marketing et Gestion de la Recherche et Developpement. Paris: Economica, Collection Recherche en Gestion.

Giard, V. (1991). Gestion de projet. Paris: Economica.

Hamel, G., Amel, G., \& Prahalad, C. K. (1995). Competing for the future. Paris: InterÉditions.

Hitt, M., \& Ireland, D. (1985). Corporate distinctive competence, strategy, industry and performance. Strategic Management Journal, 6, 273-293.

Marchesnay, M. (1997). Petite entreprise en entrepreneur. Encyclopedie de Gestion, Economica, 19, 2209-2219.

Métais, S. (1997). Intention strategique et transformation de l'environnement concurrentiel: Enjeux d'une conception de la strategie centre sur les resources de l'entreprise (These de Doctorat en Sciences de Gestion, IAE Aix en Provence, Universite d'Aix-Marseille III).

Petaraf, M. A. (1993). The cornerstones of competitive advantages: The role of firm-constituent interactions. Strategic Management Journal, 14, 179-191.

Rothaermel, F. T. (2012). Strategic management: Concepts and cases. New York: McGraw-Hill/Irwin.

Smallbone, D., Leigh, R., \& North, D. (1995). The characteristics and strategies of high growth SME's. International Journal of Entrepreneurial Behavior \& Research, 13, 44-62.

Tarondeau, J. C. (1991). Recherche et Developppement. Paris: Vuibert.

Thiétart, R. A. (2000). Gerer entre l'ordre et le chaos. Cahier de recherché DMSP, 283, 1-11.

Wernerfelt, B. (1984). A resource-based view of the firm. Strategic Management Journal, 5, 171-180. 